\title{
A Test of Soccer Cleats Compared to Football Cleats during Football Speed and Agility Drills: Do Soccer Cleats Make You Faster or More Agile?
}

\author{
Benjamin R. Mardis ${ }^{\mathrm{a}}$, Caanan G. Gassmann ${ }^{\mathrm{a}}$, David S. Senchina ${ }^{\mathrm{a}}$
}

\begin{abstract}
Background: Football players have many options in cleat styles and designs today. Skill position players especially may opt for soccer cleats over football cleats in the belief that the soccer cleats will help them run faster. Purpose: The purpose of this study was to compare soccer cleats to football cleats during common American football field drills. Methods: Sixteen young adult males performed a circuit of four American football speed and agility drills (forty yd-dash, ladder drill, 5-10-5-drill, and six-route route tree) in both soccer and football cleats. Performance measures (such as time or steps) were recorded for each drill. Subjects were asked to score the shoes in terms of comfort, heaviness, stability, and traction at various times.

Results: Two significant differences were found as a result of this study. Out route times (seconds) were significantly different between football cleats and soccer cleats. The other significant difference occurred in the perceived heaviness of each cleat. Conclusion: This study found minimal difference between football and soccer cleats in performance and perception. Participants in this study showed split preferences as to which cleat was better for performance. Of four studied perceptual outcomes, only the heaviness perception was significantly different. This was further backed by performance data that had only one significant difference among seventeen performance-associated measurements.
\end{abstract}

Keywords: Performance; Cleats; Football; Soccer

\section{Introduction}

Footwear selection is important for field sports such as American football and soccer (Caselli, 2006; Conenello, 2010; Kashuk, Savard, \& Smith, 2010). This paper will refer to football and soccer shoes as "cleats" and the various attachments to the soles as "studs." Field cleat design affects injury incidence (Bentley, Ramanathan, Arnold, Wang, \& Abboud, 2011; Hennig, 2011; Iacovelli et al., 2013; Lambson, Barnhill, \& Higgins, 1996; O'Connor \& James, 2013; Thomson, Whiteley, \& Bleakley, 2015), performance (Sterzing, Müller, Hennig, \& Milani, 2009; Sterzing, Müller, Wächtler, \& Milani, 2011), and athlete perceptions of their footwear (Daack \& Senchina, 2014; Hennig, 2014; Hennig \& Sterzing, 2010; Kinchington, Ball, \& Naughton, 2011). Athletes have a large variety of field cleats to choose from varying in the number and arrangement of studs, materials used, shoe height, and shoe mass - to name just a few differences. Most field cleat research has focused on stud configurations and numbers, specifically in the context of injuries and turf types, as reviewed elsewhere (Wei \& Meyer, 2013).

Less is known about how field cleat design affects athlete performance or perception, though shoe design impacts these (Hennig, 2011). Most research has been soccer-focused. Regarding perception in the context of field cleat design, most of the published literature has focused on comfort. In a survey, soccer athletes ranked comfort, stability, and traction as the three most important perceptions when selecting soccer cleats (Hennig, 2011), but no specific cleats were tied to the survey. A different study looked at plantar and dorsal pressures across the foot surface when wearing a diverse panel of soccer cleat models and how they impacted on comfort, but provided few details about the models tested or recommendations (Hennig \& Sterzing,
2010), and an aforementioned study looked at comfort in the context of field type (Nédélec et al., 2013). No similar surveys or studies could be found for football cleats. Four studies using football cleats and four using soccer cleats assessed athlete perception of comfort, fit, heaviness, stability, and/or traction based on shoe height, insoles, sleeves, or ankle taping and spatting (Cutts, 2013; Daack \& Senchina, 2014; Faganel, Drake, Dahl-Miller, \& Senchina, 2013; Nunns, Dixon, Clarke, \& Carré, 2015; Reuter, Dahl, \& Senchina, 2011; Sterzing \& Hennig, 2005; Sterzing, Wulf, Qin, Cheung, \& Brauner, 2014; Stryker, 2014).

Even less is known about field cleat design and performance. Studies using soccer cleats reported differences in soccer drill performance time based on stud characteristics (Brizuela, Ferrandis, Alcántara, Martinez, \& Forner, 1998; Sterzing et al., 2009). Two other soccer studies looked at performance in the context of field surface, but used the same cleats for all trials and thus did not test cleat effects (Gains, Swedenhjelm, Mayhew, Bird, \& Houser, 2010; Nédélec et al., 2013). A separate study of football cleats showed shoe height did not significantly affect performance time in acute drills (Daack \& Senchina, 2014). Some studies investigated performance and perceptual outcomes jointly (Daack \& Senchina, 2014; Kinchington, Ball, \& Naughton, 2012; Sterzing et al., 2011, 2014), and this is important due to the impact that athlete proprioception or somatosensory perception can have on performance (Kinchington et al., 2012). Intriguingly, when asked to choose between performance benefits or safety/fit, athletes will opt for clothing that they perceive as making them faster (Berggren Torell, 2011). Because these studies are patchwork, a complete "story" about field cleat design and athlete performance or athlete perception of footwear cannot be made. 
Our experiment started with an observation that many high school and college football players were switching from football cleats to soccer cleats. This was presumably because the athletes thought soccer cleats would improve their performance. The scientific literature (see above) could not address the question. The closest - and only—study we could locate directly comparing football versus soccer cleats studied only high school athlete knee injury rates (Torg \& Quedenfeld, 1971, 1973). We wanted to test whether performance times during football field drills differed whether an athlete was wearing football or soccer cleats. Our first hypothesis was that athletes would be able to complete a variety of football speed and agility drills more quickly wearing soccer cleats compared to football cleats. We also wanted to test how the cleat types influenced the athletes' perceptions of footwear comfort, heaviness, stability, traction, and overall preference. Our second hypothesis was that the soccer cleat would be perceived as more comfortable, less heavy, less stable, having better traction, and being generally preferred compared to the football cleat.

\section{Experimental Procedures}

All procedures were approved by the Drake University Institutional Review Board (ID 2012-13013). Before their giving written consent, each subject was given details pertaining to the study with a chance to ask any questions they had of the study. Sixteen males between the ages of 18 and 35 were used for this study. These individuals were regular exercisers and safely able to perform the tests in this study. Subjects could fit into Nike soccer and football cleats at men's size 10-12 shoe. To limit biases, none of the subjects currently played collegiate soccer, nor collegiate football. The anthropometrics of each subject were as follows (expressed as averages \pm standard error): age $21.1 \pm 5.6$, height $179.7 \pm$ $8.4 \mathrm{~cm}$, weight $71.8 \pm 11.3 \mathrm{~kg}$. The average mass of subjects' personal training shoes was $324.2 \pm 56.4 \mathrm{~g}$.

One model of football cleat (Nike Land Shark Legacy Low) and one model of soccer cleat (Nike Mercurial Vortex FG) were tested by each subject (Figures 1 and 2; Table 1). As Figs. 1 and 2 demonstrate, both cleats allowed for free range-of-motion of the ankle malleoli. All cleats were bought new at the start of the study. These models were selected for comparison because both represent "low-end" models from the same manufacturer, and would be equivalent price-point purchases from a consumer's perspective. Each subject was given calf-high crew socks made by Body Glove Incorporated ( $98 \%$ polyester and $2 \%$ spandex), to minimize variance. Subjects participated in two identical training circuits consisting of four drills (described in more detail below). Each subject went through all four drills before switching cleats. Before, midway, and after each circuit subjects were asked to rate each model based on their perceived comfort, heaviness, stability, and traction using $10-\mathrm{cm}$ visual analogue scales (VAS).

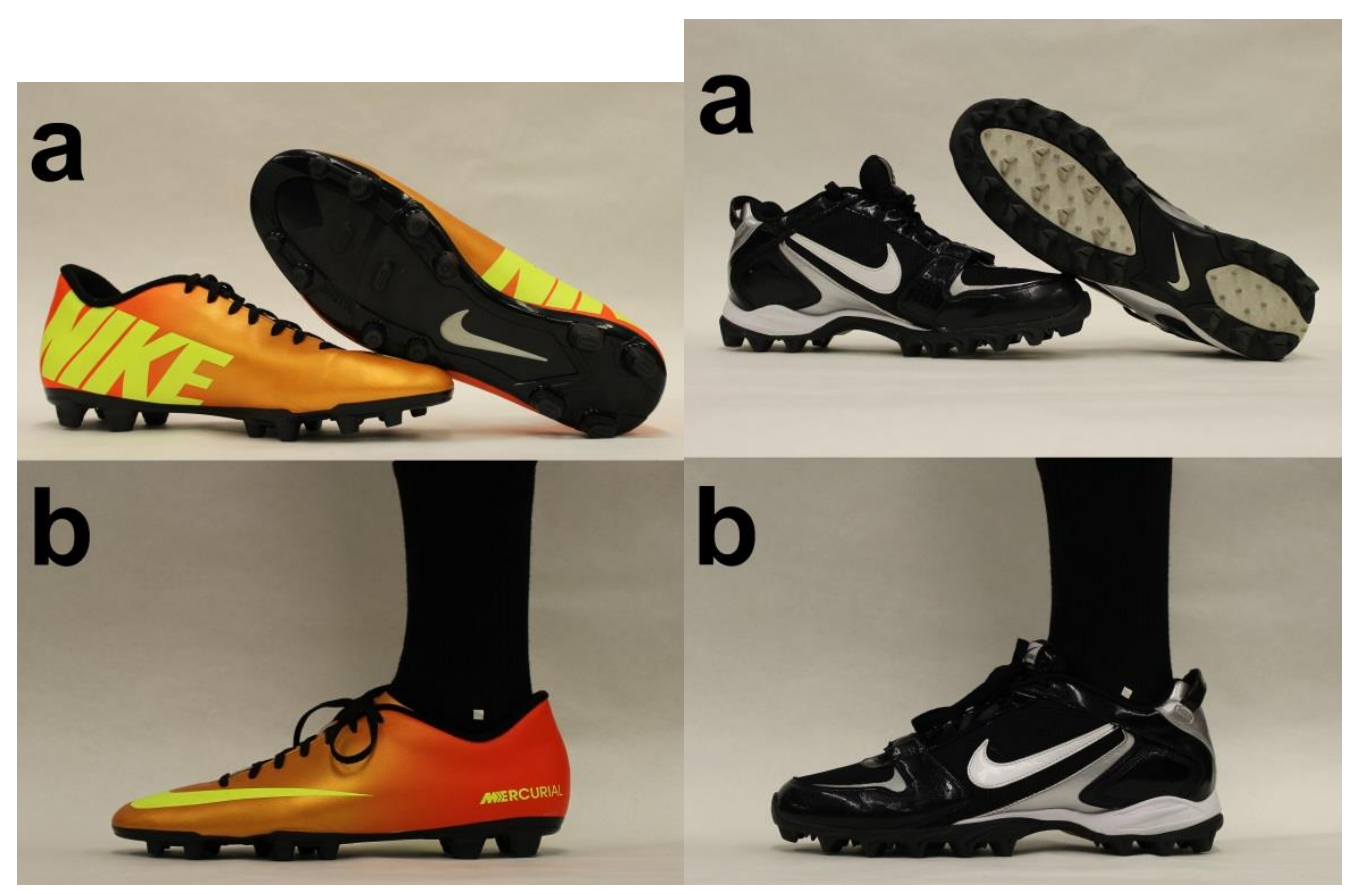

Figure 1. Soccer cleat. (a) Medial side and sole. (b) Lateral side. The white tape mark shows the ankle Malleolus.

Figure 2. Football cleat. (a) Medial side and sole. (b) Lateral side. The white tape mark shows the ankle Malleolus 


\begin{tabular}{|c|c|c|c|c|c|c|c|c|c|c|c|}
\hline & Size & $\begin{array}{c}\text { Mass } \\
(\mathbf{g}) \\
\end{array}$ & $\begin{array}{c}\text { Height } \\
(\mathbf{c m})\end{array}$ & $\begin{array}{c}\text { Length } \\
(\mathrm{cm})\end{array}$ & $\begin{array}{c}\text { Ball } \\
\text { Girth } \\
(\mathbf{c m})\end{array}$ & & Size & $\begin{array}{c}\text { Mass } \\
(\mathbf{g}) \\
\end{array}$ & $\begin{array}{c}\text { Height } \\
(\mathbf{c m})\end{array}$ & $\begin{array}{c}\text { Length } \\
(\mathrm{cm})\end{array}$ & $\begin{array}{c}\text { Ball } \\
\text { Girth } \\
(\mathbf{c m})\end{array}$ \\
\hline \multirow[t]{4}{*}{ Soccer } & 10.5 & 244.3 & 7 & 29 & 9.5 & Football & 10 & 411.1 & 9.25 & 29.5 & 9.5 \\
\hline & 11.5 & 258.8 & 7.25 & 30 & 9.75 & & 11 & 435.1 & 9.25 & 30.5 & 9.75 \\
\hline & 12 & 264.5 & 7.25 & 30.5 & 10 & & 11.5 & 433.7 & 9.5 & 31 & 10 \\
\hline & 12.5 & 265.7 & 7.5 & 31 & 10 & & 12 & 456.4 & 9.75 & 31.5 & 10 \\
\hline
\end{tabular}

Table 1. Physical properties of the soccer and football cleats. Each row represents the correct soccer-football cleat pairing (per manufacturer's instructions, the soccer cleat should be ordered $1 / 2$ size larger than standard shoe size, so a men's size 10.5 soccer cleat pairs with a men's size 10 football cleat). Height was measured from the bottom of the sole to the malleolar notch. Ball girth was measured at the widest part of the forefoot of the sole.

Subjects completed two identical circuits that consisted of four drills, once in soccer and once in football shoes, in counterbalanced order. The circuit was always performed in the same order as follows: 40-yard dash, ladder drill, 5-10-5 drill, and route tree. Different performance outcomes were recorded for each station. For the 40-yard dash, subjects started at the goal line ( 0 -yard line) and sprinted to the 40yard line. Their time was recorded along with their 20-yard deceleration time. The number of steps they took during the 40 -yard dash and 20-yard deceleration was recorded. For the ladder drill, a standard agility ladder (SKLZ Quick Ladder Agility Trainer; SKLZ/Pro Performance Sports, Carlsbad, CA) was used. Subjects ran the ladder by starting on one end, placing the left foot in one square then the right foot in the same square, and then repeating this pattern for adjacent squares to the end of the ladder; upon reaching the end, they tapped one foot out and repeated the course in reverse. Each subject was asked to run the ladder drill for a fixed 15 seconds. Total number of steps and number of missteps (foot out of sequence or on the ladder) were counted. For the 5-105 (ProAgility) drill, subjects started on the 30-yard line with their dominant hand on the ground. Time was taken for how long it took them to sprint to the 25-yard line (touch that line) and sprint to the 35-yard line (touch that line) and finally sprint through the 30 yard line. Subject missteps (not hitting the sideline properly) and time to complete the drill were counted. For the route tree, disc cones were set up on the field to indicate target spots for subjects to run to. Six routes were run, always in the same order: in, out, post, flag, curl-in, and curl-out (Figure 3). Subjects ran a straight 10 yards out before breaking for each route, then 10 yards through completion of the in, our, post, and flag routes, or 5 yards in the case of the curl-in and curl-out routes. Subjects were timed for how long it took them to run each route, their number of steps for the out and post routes (as representative routes), and their total number of missteps (if any) for all routes combined (failure to hit the 10 -yd disc cone).

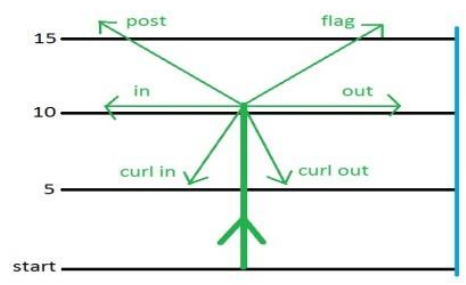

Figure 3. Running patterns for the six routes in the route tree. Further details are provided in
Data was entered into Microsoft Excel for analysis. The performance data (times, steps, and/or missteps across the four drills) were analyzed by paired samples t-tests comparing the football cleat versus the soccer cleat in SPSS v. 23 (IBM, Inc.) The perceptual data (comfort, heaviness, stability, traction) were analyzed by ANOVA in SPSS, with shoe (football vs. soccer) and time point (before, during, and after exercise) being the independent variables and VAS score being the dependent variable. For all analyses, significance was defined as $p<0.05$.

\section{Results}

Performance outcomes are shown in Table 2. Of the seventeen performance-associated measurements in this study, only one was significantly different between soccer and football cleats - subjects ran the out route faster in football cleats than in soccer cleats $(\mathrm{p}=0.012)$.

Perceptual scores are shown in Table 3. There was never a significant effect of time (before, during, or after) for any of the perceptions. Of the four perceptual outcomes, subjects only perceived a significant difference in heaviness between the football cleats and the soccer cleats such that the football cleats were consistently perceived as heavier $(p<0.001)$. There was never a significant time $\times$ shoe interaction.

The sixteen subjects were split with respect to overall cleat preference-8/16 $(50 \%)$ preferred the soccer cleat and the other 8/16 (50\%) preferred the football cleat. When asked why they preferred one cleat over the other, subjects gave various reasons, and sometimes a single subject gave more than one reason. Traction ( 5 for soccer, 5 for football) was the most common reason, followed by fit ( 2 for soccer, 2 for football), stability ( 1 for soccer, 3 for football), "felt light" ( 0 for football, 2 for soccer), or comfort (1 for soccer, 1 for football). Subjects were also specifically asked which cleat they preferred the appearance of, and 10/16 (63\%) preferred the look of the soccer cleat whereas $6 / 16(37 \%)$ preferred the look of the football cleat. 


\begin{tabular}{llccc}
\hline \hline & & Soccer Cleat & Football Cleat & p-value \\
\hline \multirow{2}{*}{ 40-yd Dash } & time (s) & $5.3 \pm 0.6$ & $5.2 \pm 0.5$ & 0.860 \\
& \# steps & $21.9 \pm 2.6$ & $21.4 \pm 2.4$ & 0.069 \\
& deceleration time (s) & $2.1 \pm 0.8$ & $2.0 \pm 0.7$ & 0.689 \\
& deceleration \# of steps & $10.8 \pm 3.5$ & $10.5 \pm 3.3$ & 0.352 \\
\hline \multirow{2}{*}{ Ladder Drill } & \# total steps & $83.4 \pm 13.6$ & $81.7 \pm 11.6$ & 0.551 \\
& \# missteps & $8.3 \pm 3.7$ & $10.3 \pm 7.4$ & 0.259 \\
\hline \multirow{2}{*}{ 5-10-5 Drill } & time (s) & $5.0 \pm 0.5$ & $5.0 \pm 0.5$ & 0.646 \\
& \# missteps & $0.4 \pm 0.7$ & $0.2 \pm 0.4$ & 0.083 \\
\hline \multirow{2}{*}{ Tree } & in route time (s) & $3.7 \pm 0.3$ & $3.8 \pm 0.3$ & 0.689 \\
& post route time (s) & $3.7 \pm 0.4$ & $3.7 \pm 0.4$ & 0.957 \\
& curl-in route time (s) & $3.6 \pm 0.5$ & $3.5 \pm 0.5$ & 0.300 \\
& out route time (s) & $3.9 \pm 0.3$ & $3.7 \pm 0.3$ & $0.012^{*}$ \\
& flag route time (s) & $3.7 \pm 0.4$ & $3.6 \pm 0.4$ & 0.480 \\
& curl-out route time (s) & $3.5 \pm 0.5$ & $3.5 \pm 0.5$ & 0.847 \\
& post route \# steps & $15.5 \pm 2.6$ & $15.0 \pm 2.3$ & 0.400 \\
& out route \# steps & $16.4 \pm 4.5$ & $17.0 \pm 4.2$ & 0.333 \\
& entire tree \# missteps & $0.6 \pm 0.8$ & $0.9 \pm 1.0$ & 0.261 \\
\hline \hline
\end{tabular}

Table 2. Performance outcomes for the four football drills. Values are averages \pm standard deviation. Asterisks $(*)$ indicate a statistically-significant difference $(\mathrm{p} \leq 0.05)$.

\begin{tabular}{lllccc}
\hline \hline \multirow{5}{*}{ Comfort } & $\begin{array}{c}\text { Time } \\
\text { Point }\end{array}$ & Soccer Cleat & Football Cleat & $\begin{array}{c}\text { p-value } \\
\text { (shoe type) }\end{array}$ & $\begin{array}{c}\text { p-value } \\
\text { (time) }\end{array}$ \\
\hline \multirow{5}{*}{ Heaviness } & Before & $5.9 \pm 2.2$ & $6.2 \pm 1.8$ & 0.968 & 0.655 \\
& During & $6.0 \pm 1.9$ & $6.1 \pm 2.1$ & & \\
& After & $5.9 \pm 2.1$ & $5.4 \pm 2.0$ & & \\
& Before & $2.3 \pm 1.4$ & $5.7 \pm 1.9$ & $<0.001 *$ & \\
& During & $2.3 \pm 1.8$ & $5.8 \pm 1.9$ & & \\
& After & $2.9 \pm 1.9$ & $6.0 \pm 2.3$ & & \\
& Before & $6.3 \pm 1.7$ & $6.3 . \pm 1.7$ & \\
& During & $6.3 \pm 1.5$ & $6.9 \pm 1.3$ & & \\
& After & $5.5 \pm 1.7$ & $5.9 \pm 2.3$ & & \\
& Before & $6.7 \pm 1.8$ & $6.2 \pm 1.6$ & 0.919 & \\
& During & $6.4 \pm 1.8$ & $6.8 \pm 1.6$ & & \\
& After & $5.8 \pm 2.1$ & $5.8 \pm 2.3$ & & \\
\hline \hline
\end{tabular}

Table 3. Perceptual outcomes before, during (midway, after 2 of the 4 drills), and after the drills. Values are $\mathrm{cm}$ on the VAS (see Experimental Procedures) and shown as averages \pm standard deviation. Asterisks $(*)$ indicate a statistically-significant difference $(\mathrm{p} \leq 0.05)$.

Discussion

The main finding of this study was an overall lack of perceptual or performance differences between the football cleat trials and the soccer cleat trials. Subjects were equally split on their overall preference of cleat. While they 
consistently (and accurately) perceived the football cleats as being heavier than the soccer cleats, they did not perceive differences in comfort, stability, or traction. Performance times were no different between the two cleats with the exception of one of the routes which, in comparison to the total data, is likely not meaningful. Thus, the results do not suggest that a football athlete would gain any performance advantage from wearing a low-top soccer cleat instead of a low-top football cleat.

To the best of our knowledge, this study is the first to examine differences between football cleats and soccer cleats in terms of performance or perception, which means there are no other published studies for direct comparison. A few studies have reported difference in stud design or configuration and performance or perception differences (Hennig \& Sterzing, 2010; Müller, Sterzing, Lake, \& Milani, 2010), but the designs are not described in enough detail to compare with the cleats used in this study, possibly because the studies were industry-funded and may have needed to preserve proprietary information. One finding that is clear from such studies is that athlete perceptions of factors such as comfort or stability have a direct relationship to performance (Hennig, 2011; Kinchington et al., 2012; Sterzing \& Hennig, 2005), and that with repeated use athletes make both acute and chronic "neuromotor adaptations" to different footwear (Hennig, 2011). Such acute "neuromotor adaptations" may explain the lack of performance differences in our study.

This study has some limitations. Athletes were tested under practice/drills conditions and not game conditions, which may have influenced results; however, previous research has established conditions such as those used in the present study are preferable to game conditions for footwear testing, because game conditions are complex situations which reduce perceptual ability (Sterzing \& Hennig, 2005). Athletes in this study came from a variety of athletic backgrounds, and differences in training or skills may have contributed to variation in the data. A larger sample size may have produced different results. All performance outcomes were hand-timed, and it is possible that electronic timing may have detected subtle differences not found from manual timing (Gains et al., 2010). Weather conditions varied as data was collected across multiple months over two autumn semesters, which may have led to different field conditions or athlete mindsets (though trials were always performed on dry turf). Future studies might be better performed with more controlled indoor conditions. Though both the football and soccer cleats tested in this study had molded studs, their shape and number were different (Figs. 1 and 2; the football cleat having more and varied stud shapes); however, given the literature cited in the preceding paragraph, those different features likely did not influence the results. However, the appearance of the shoes may have biased subjects.

From this study there are several possible future studies. We used Nike cleats that represented the "low-end" models from the same manufacturer, and would be equivalent pricepoint purchases from a consumer's perspective; however, future studies could explore "high-end" models (which, in theory, might display more significant performance or perception differences due to their higher quality or more pronounced differences). Alternatively, comparing football versus soccer shoes from a different brand may provide different results and, coupled with this study, overall more generalizable findings. Addressing the aforementioned variability in athletes, a future study could test a population of athletes from a single male sport (such as tennis, given its high endurance training) to reduce athlete background variability; or could test football and soccer players (despite their predicted a priori biases, as explained in Methods) to see how bias influences results, especially in comparison to a study such as this one, which attempted to reduce such bias.

\section{Acknowledgments}

We'd like to thank all the subjects that volunteered for our study, especially those that came out on some unseasonably cold November days. Michael Ball (in 2013) and Brady Randall and Zach Elsbecker (in 2015) from Athletics coordinated field reservations for our classes. Students in FYS 19 "Running: Body, Mind, Sole" (in 2013) and BIO 31 "Kinesiology Orientation" (in 2015) assisted with data collection, subject recruitment, and some preliminary analyses.

\section{References}

Bentley, J. A., Ramanathan, A. K., Arnold, G. P., Wang, W., \& Abboud, R. J. (2011). Harmful cleats of football boots: a biomechanical evaluation. Foot and Ankle Surgery, 17(3), 140-144. http://doi.org/10.1016/j.fas.2010.04.001

Berggren Torell, V. (2011). As Fast as Possible Rather Than Well Protected Experiences of Football Clothes. Culture Unbound: Journal of Current Cultural Research, 3(1), 83-99. http://doi.org/10.3384/cu.2000.1525.11383

Brizuela, G., Ferrandis, R., Alcántara, E., Martinez, A., \& Forner, A. (1998). Biomechanical design of football boots: Effects of studs on performance and injury prevention. ISBS - Conference Proceedings Archive, 1(1). Retrieved from https://ojs.ub.unikonstanz.de/cpa/article/view/951

Caselli, M. A. (2006). Selecting the proper athletic shoe. Podiatry Management, 25(8), 147-156.

Conenello, R. M. (2010). Soccer. In M. B. Werd \& E. L. Knight (Eds.), Athletic Footwear and Orthoses in Sports Medicine (pp. 239-246). Springer New York. Retrieved from http://link.springer.com/chapter/10.1007/978-0387-76416-0_21

Cutts, M. (2013, September 4). The Effect of External Ankle Support on Football Specific Performance Tests and the Perception of the Athletes that Wear Them (Master's Thesis). Retrieved from http://scholars.indstate.edu/handle/10484/5368

Daack, C. W., \& Senchina, D. S. (2014). A Field Study of Low-Top vs. Mid-Top vs. High-Top American Football Cleats. Sports, 2(4), 85-98. http://doi.org/10.3390/sports2040085

Faganel, P. P., Drake, T. C., Dahl-Miller, A. R., \& Senchina, D. S. (2013). Height variations in football shoes (cleats) for running backs and receivers may not alter ankle spatting effects in football field drills. Journal of Undergraduate Research, 4(1), 6-10.

Gains, G. L., Swedenhjelm, A. N., Mayhew, J. L., Bird, H. M., \& Houser, J. J. (2010). Comparison of speed and agility performance of college football players on field 
turf and natural grass. Journal of Strength and Conditioning Research, 24(10), 2613-2617. http://doi.org/10.1519/JSC.0b013e3181eccdf8

Hennig, E. M. (2011). The influence of soccer shoe design on player performance and injuries. Research in Sports Medicine, 19(3), 186-201. http://doi.org/10.1080/15438627.2011.582823

Hennig, E. M. (2014). Plantar pressure measurements for the evaluation of shoe comfort, overuse injuries and performance in soccer. Footwear Science, 6(2), 119-127. http://doi.org/10.1080/19424280.2013.873486

Hennig, E. M., \& Sterzing, T. (2010). The influence of soccer shoe design on playing performance: a series of biomechanical studies. Footwear Science, 2(1), 3-11. http://doi.org/10.1080/19424281003691999

Iacovelli, J. N., Yang, J., Thomas, G., Wu, H., Schiltz, T., \& Foster, D. T. (2013). The effect of field condition and shoe type on lower extremity injuries in American Football. British Journal of Sports Medicine, 47(12), 789-793. http://doi.org/10.1136/bjsports-2012-092113

Kashuk, K. B., Savard, M., \& Smith, T. (2010). Football. In M. B. Werd \& E. L. Knight (Eds.), Athletic Footwear and Orthoses in Sports Medicine (pp. 225-237). Springer New York. Retrieved from http://link.springer.com/chapter/10.1007/978-0-38776416-0_20

Kinchington, M. A., Ball, K. A., \& Naughton, G. (2011). Effects of footwear on comfort and injury in professional rugby league. Journal of Sports Sciences, 29(13), 14071415. http://doi.org/10.1080/02640414.2011.593041

Kinchington, M. A., Ball, K., \& Naughton, G. (2012). Relation between lower limb comfort and performance in elite footballers. Physical Therapy in Sport, 13(1), 2734. http://doi.org/10.1016/j.ptsp.2011.02.001

Lambson, R. B., Barnhill, B. S., \& Higgins, R. W. (1996). Football cleat design and its effect on anterior cruciate ligament injuries. A three-year prospective study. The American Journal of Sports Medicine, 24(2), 155-159.

Müller, C., Sterzing, T., Lake, M., \& Milani, T. L. (2010). Different stud configurations cause movement adaptations during a soccer turning movement. Footwear Science, 2(1), 21-28. http://doi.org/10.1080/19424281003685702

Nédélec, M., McCall, A., Carling, C., Le Gall, F., Berthoin, S., \& Dupont, G. (2013). Physical performance and subjective ratings after a soccer-specific exercise simulation: comparison of natural grass versus artificial turf. Journal of Sports Sciences, 31(5), 529-536. http://doi.org/10.1080/02640414.2012.738923

Nunns, M. P. I., Dixon, S. J., Clarke, J., \& Carré, M. (2015).
Boot-insole effects on comfort and plantar loading at the heel and fifth metatarsal during running and turning in soccer. Journal of Sports Sciences, O(0), 1-8. http://doi.org/10.1080/02640414.2015.1069378

O’Connor, A.-M., \& James, I. T. (2013). Association of lower limb injury with boot cleat design and playing surface in elite soccer. Foot and Ankle Clinics, 18(2), 369-380. http://doi.org/10.1016/j.fcl.2013.02.012

Reuter, G., Dahl, A., \& Senchina, D. (2011). Ankle spatting compared to bracing or taping during maximal-effort sprint drills. International Journal of Exercise Science, 4(1), 49-64.

Sterzing, T., \& Hennig, E. (2005). Stability in soccer shoes: The relationship between perception of stability and biomechanical parameters. In Science and Football V: Proceedings of the Fifth World Congress on Science and Football (pp. 45-50). London: Routledge.

Sterzing, T., Müller, C., Hennig, E. M., \& Milani, T. L. (2009). Actual and perceived running performance in soccer shoes: A series of eight studies. Footwear Science, 1(1), 5-17. http://doi.org/10.1080/19424280902915350

Sterzing, T., Müller, C., Wächtler, T., \& Milani, T. L. (2011). Shoe influence on actual and perceived ball handling performance in soccer. Footwear Science, 3(2), 97-105. http://doi.org/10.1080/19424280.2011.552439

Sterzing, T., Wulf, M., Qin, T. Y., Cheung, J. T.-M., \& Brauner, T. (2014). Effect of soccer shoe ball girth differences on fit perception, agility running and running speed perception. Footwear Science, 6(2), 97-103. http://doi.org/10.1080/19424280.2014.886084

Stryker, S. (2014). Comparing athletic performance, stability, and comfort in athletes wearing the Under Armour(RTM) Blue cleat in different conditions (Master's). University of Delaware, Newark, DE.

Thomson, A., Whiteley, R., \& Bleakley, C. (2015). Higher shoe-surface interaction is associated with doubling of lower extremity injury risk in football codes: a systematic review and meta-analysis. British Journal of Sports Medicine, 49(19), 1245-1252. http://doi.org/10.1136/bjsports-2014-094478

Torg, J. S., \& Quedenfeld, T. (1971). Effect of shoe type and cleat length on incidence and severity of knee injuries among high school football players. Research Quarterly, 42(2), 203-211.

Torg, J. S., \& Quedenfeld, T. (1973). Knee and ankle injuries traceed to shoes and cleats. Physician and Sportsmedicine, 1, 39-43.

Wei, F., \& Meyer, E. G. (2013). Footwear properties and football injuries. Lower Extremity Review, 5(2). 